\title{
Critical Review on the Meaning, Purposes and Techniques of Integrative Language Skills Teaching Approach
}

\author{
Amarech Alaye* Wondimu Tegegne** \\ Wolaita Sodo University
}

\begin{abstract}
In an age of globalization, the objectives of language skill learning and teaching is for meaningful communication and the development of learners'communicative competence. Meaningful communication requires the integration of the various language skills. In the integrated language skills instruction, learners are exposed to authentic language and are involved in activities that are meaningful and interesting. The four macro English language skills are all an integral part of typical language proficiency and use. For example, by practicing conversational skills the learner can focus not only on speaking but also listening, in order to react and ask appropriate follow-up question. Skill integration also happens when students are involved in project work, which may well involve examining through reading, listening, speaking (e.g. in discussions or when giving a presentation to the audiences and writing to submitting a report. Thus, the four English skills should not be taught in isolation but integratively in the classroom through an integrated approach. An integrated language skills teaching approach is an approach whereby language skills are taught integratively. With this regard, the main objective of this article is to critically review the meaning, purposes and techniques of integrative language skills teaching approach. To achieve this objectives various, books, book chapters, guidelines, research findings and documents were critically reviewed and analyzed. Therefore, this article describes the features and problems of segregated approach to language teaching. Then, it explains the meaning and purpose of the integrative language skill teaching and historical background and current perspective of it. Finally, the article describes the methods and techniques of integrative language skills teaching approach.

Keywords: Integrative, Language Skills, Teaching, Approach, methods, techniques, language teaching
\end{abstract} approach, learning

DOI: $10.7176 /$ JLLL/58-03

Publication date:July $31^{\text {st }} 2019$

\section{Segregated Language Skill Teaching Approach}

Before the development of communicative language teaching (CLT), which was before1960s, one or two of the four language skills were given prominence in English as a foreign language classes, where one or two language skills were dominant over the others. Oxford (2001) expresses this approach as segregated language teaching skill approach, it is reflected in traditional English as a foreign language/English as second language curriculum that offer classes more focused on segregated language skills. Segregated Language Skill Teaching Approach (SLTA) was found to be contradictory to the natural way of acquiring a language and there has been a movement to integrated language skill teaching approaches that encourage the teaching of all four skills in integrative way. In real life communication, language skills are rarely used in isolation; it is a unusual situation where the four skills occur alone, teaching language skills in isolation leads to distinction between actual classroom situation and real life language use (Jing, 2006).

In the segregated-skill approach, the mastery of discrete language skills such as reading, grammar, vocabulary and speaking were seen as the key to successful learning, and language learning was typically separated. It is reflected in the traditional language teaching methods that offer classes focusing on one-off language skills. With this regard, educators think it is logistically easier to present courses on writing divorced from speaking, or on listening isolated from reading. They also believe that it is instructionally impossible to concentrate on more than one skill at a time (Olga and Anastasia, 2012).

Even though segregated language skill teaching approach was possible to fully develop one or two skills in the absence of all the others, it would be difficult to be successful in academic communication, career-related language use, or everyday interaction in the language. An example of SLTA is the grammar-translation method. In this method teachers and students analyze grammar and translate (usually in writing) from one language to another. This method restricts language learning to a very narrow, non-communicative range that does not prepare students to use the language in everyday life (Olga and Anastasia, 2012) .

Moreover, Jing (2006) expresses that traditional English teaching approach often taught the four language skills separately and materials and activities designed usually focused on one specific skill and others were ignored. In the past, listening and reading skills in English as a foreign language were not considered as much important as speaking and writing. The segregation of the skills is not consistent with the nature of language development in the first language context. In the first language context, all language skills are interrelated. The interrelatedness of the language skills can be deduced from observation of a child's development of oral and 
written language which follows the sequence of listening, speaking, reading, and writing. In connection to this, Strang (1972) states that child's listening skill precedes speaking and reading. Children acquire their mother tongue language through listening and imitating the speech of their parents. The weaknesses of this approach leads to the emergency of the integrative language teaching approach.

\section{The Meaning and Purpose of Integrative Language Skills Teaching Approach}

An integrative approach is the approach of teaching language skills simultaneously. This means the four macro skills (reading, writing, speaking, and listening) are taught concurrently. Richards, Platt, and Weber (1988: 144) define it as "integrated language skills teaching approach is "the teaching of the language skills of reading, writing, listening, and speaking in conjunction with each other as when a lesson involves activities that relate listening and speaking to reading and writing." According to Afnan, (2014), integrating language teaching approach is vital technique for effective language learning. This technique refers to including two or more than two language skills, in a lesson/ task. Richards and Schmidt (2010) as cited in Afnan 2014 also define this approach as relating reading, writing, speaking, and listening together in activity that can be taught via a holistic method. Integrating language skills teaching can be described as a whole-language approach or a multi-skill syllabus. This is because the approach teaches all the language skills together.

Integrated language skills teaching approach is a whole language approach. That is, if a lesson deals with reading skills, then, it will also deal with listening, speaking, and writing skills. It emphasizes on communication purpose in addition to academic success (Hungyo and Kijai 2009 as cited in Elena and Lorena 2011). The four English language skills can be taught integratively in the actual classroom situation via integrative approach. For example, by practicing conversational skills the learner can focus not only on speaking but also listening, in order to reply and ask appropriate follow-up questions. All language skills are considered and to be essential components to develop the communicative competence of students, the skills should be taught together via interactive language teaching approach. Thus, the approach advocates integration of all language skills in actual classroom situation (Crystal, 2003). In other words, integrated language skill teaching approach is the natural way of learning a language. In real life communication, language skills are rarely used in isolation; it is a rare situation where one of the four skills occurs alone. For example, to engage in a conversation, one needs to be able to speak and comprehend at the same time (Jing,2006).

In terms of integration skill Oxford (2001) introduces the concept of tapestry, it is woven from different strands including the teacher, learner, setting, and relevant languages besides four skills. She believed that absence of such threads may lead to a discrete, segregated skills-like in a real tapestry parallel threads not touching, supporting, or interacting with each other. Additionally she argue that in integrative language skill teaching includes associated or related skills such as knowledge of vocabulary, spelling, pronunciation, syntax, meaning, and usage. According to her, this forms an integrated language teaching approach.

In effective lessons language teachers must be integrate language skills simultaneously in order to make language learning as realistic as possible which is a requisite in communication. Often one skill will reinforce another; we learn to speak, for example, in part by modeling what we hear, and we learn to write by examining what we can read (Brown, 2001). For instance, teaching reading can be easily tied to instruction on writing and vocabulary, and oral skills readily lend themselves to teaching pronunciation, listening, and cross-cultural pragmatics (Hinkel, 2001; Lazaraton, 2001; McCarthy and O`Keeffe, 2004).

Moreover, educators(such as Fotos,2002; Ellis, 2003; Snow, 2005) argue that integrative language skill instruction can increase learners opportunities for language learning and purposeful communication, interaction, real-life language use and diverse types of contextualized discourse and linguistic features, all of which have the goal of developing students language proficiency and skills. When the four primary skills of language: listening, reading, speaking and writing are interwoven during instruction, it helps us emulate real-life language use and it also paves the way for optimal language learning to take place (Oxford, 2001). In addition to this purposes, integration of four skills can develop communicative competence, because the real life demands from the learners not only immersion into the knowledge of language, but also into the knowledge about how to use the language appropriately in communicative situations( Jing,2006). Other scholars confirm that language learning tasks should be designed in an integrative manner(McDonough and Shaw, 2003). This helps students to be involved in language tasks that integrate different language skills and advance their skills (Hulstijn and Laufer, 2001).

From the above discussion, it can understand that integrated language teaching skill approach is the usual way of learning a language and allows teachers to track students' progress in multiple skills at the same time. Integration of language skills will expose learners to actual language use and encourage interaction (Oxford, 2001). Language teachers can integrate language skills by using different ways in the class room that can accelerate teaching learning process. With this regard, the current study explored the attitude and awareness of teachers and students towards the integrative language teaching Approach. It also describes how English language teachers implement integrative language teaching approach in actual classroom. 


\section{Integrative Language Skill Teaching Approach: The Past and Current Perspective}

With the spread of English as a lingua franca and as the medium for world-wide broadcasting of information and knowledge, in many cases, the pragmatic objectives of language learning emphasize the importance of integrated language skill teaching and flexible instruction. (Celce-Murcia, 2001; Kaplan, 1991). In general, insight on current language curriculum, teaching reading is typically associated to instruction on writing and vocabulary, teaching writing can be easily tied to reading and grammar, and speaking skills readily lend the learners to teaching listening, pronunciation, and cross-cultural pragmatics (Hinkel, 2001).

As early as 1970, many scholars (such as Corder, 1978; Kaplan, 1970; Stern, 1992) stated that the teaching of language skills cannot be conducted through isolable and discrete structural elements since language skills are not divorced from each other. Widdowson (1978) was one of the first linguists to call for integrating the four language skills in instruction to increase learners' proficiency levels and to empower their language learning. In light of the fact that, in the 1980s and 1990s, a great deal of elaboration and refinement took place in communicative and integrated teaching of the four skills. In connection to this, Shen, (2003) confirms that the implementation of language in communication, should closely integrates linguistic competence with communicative skills and communicative culture in the process of language skill teaching. So that the learners' linguistic competence and their communicative skills can be improved simultaneously. These had to be interaction-centered and as authentic as possible to enable students to use the language skills for purposeful and effective communication (Savignon, 1990).

Meanwhile, the current models of integrated teaching of the four language skills have the objective of developing learners' fluency and accuracy, as well as their socio cultural communicative competence requiring and adapting the language from context to context and from genre to genre. With regard to this, at the present time English is widely used as the medium of international communication, it seems easy to predict that integrated language teaching will continue to dominate among the various types of pedagogical models (Hinkel,2006).

Generally, in the current situation, language skill teaching and learning recognize that, in meaningful and effective communication, educators use language skills in integrative way and ignore isolation use of language skills. Because, all skills are tied to each other and essential in successful class room situation and in meaningful communication (Hinkel, 2001; Lazaraton, 2001; McCarthy and O'Keeffe, 2004). With this regard, there are various methods which are used to teach the language skills integratively. Some of the methods are describe in the next subsection.

\section{Methods of Integrated Language Skills Teaching Approach}

With the current emphasis on both fluency and accuracy of language use, it seems clear, that integrated language skill teaching and learning as well as integrative instructional models, will need to continue to be refined and developed ( Breen, 1991; Swain, 1991). According to Richards and Rodgers (2001), integrative language skills teaching that engages learners in meaningful communication and enables them to attain their language skill learning objectives can be found in many ways, different teaching materials and techniques. A few examples of such integrated language skill teaching methods are content-based (sometimes also called theme-based), taskbased, text-based (also called genre-based), discourse-based, project-based, network-based, technology-based, corpus-based, interaction-based, literature-based, literacy-based, community-based, competency-based, or standards-based.

From the above integrative language skill teaching methods, the two common methods of integrated language skills instruction are content-based language instruction and task-based instruction(Oxford,2001) These models emphasis on learning content through language (Oxford, 2001). Both of these benefit a diverse range of materials, textbooks, and technologies for the EFL classroom. Currently, task-based and content based instruction are probably among the most widely adopted integrated models (Hinkel, 2006). Thus, in this section an attempt is made to provide brief explanation about the two common methods of integrative language teaching approach.

\subsection{Content-based Instruction (CBI) \\ 4.1.1 Definition of Content based Instruction}

Several authors have forwarded their view and definition about content based instruction. For example, according to Meet(1999)content is to represent material that is cognitively engaging and demanding for the learner, and that extends beyond the target language or target culture. In other words, content should include materials that create interest in the learners learning language, are meaningful to the life of learners, and provide messages comprehensible to the learners. According to Short (1989) as cited in Gabriela 2015, content-based language instruction is an approach that integrates second language instruction with subject matter instruction. Each lesson in a content-based class has content (e.g., math, science, social studies) and language objectives (e.g., grammar, functions). Students learn language through the context of specific subject matter rather than through 
isolated language features. This type of instruction focuses on the idea that language should not be taught in an isolated way, but rather within a meaningful context, which will not only basically motivate the learners, but also will empower them.

According to Davies (2003), CBI is a teaching method that emphasizes learning about something rather than learning about language. (Richards, 2006) also believe that content is the information or subject matter that we learn or communicate through language rather than the language used to convey it. It can be used as the framework for a unit of work, as the guiding principle for an entire course, as a course that prepares students for mainstreaming, as the rationale for the use of English as a medium for teaching some school subjects in an EFL setting, and as the framework for commercial EFL/ESL materials (Richards,2006)

Content based instruction is an ultimate approach to learning the target language (Kasper, 2000). It fits in well with broader principles of language teaching and learning, and it can be applied in various situations. It could be used efficiently in ESL as well as EFL classrooms Richards \& Rodgers, 2001).

According to Brinton, Snow and Wesche (1989: 2) CBI is

"The integration of particular content with language teaching aims, or as the concurrent teaching of academic subject matter and second language skills. In CBI approaches the second language is the medium to convey informational content of interest and relevance to the learner, rather than the immediate object of study".

In content-based instruction, students practice all the language skills in a highly integrated, communicative fashion while learning content such as science, mathematics, and social studies. This means, learning content through language. It is valuable at all levels of proficiency, but the nature of the content might differ by proficiency level (Brinton, Snow, and Wesche 1989).For beginners, the content often involves basic social and interpersonal communication skills, but past the beginning level, the content can become increasingly academic and complex). Chamot and O'Malley (1994) show how language learning strategies can be integrated into the simultaneous learning of content and language.

Content-based approach is sometimes, called content and language integrated learning (CLIL), learners are encouraged to think and learn through the use of the target language by integrating the four traditional language skills (listening, speaking, reading and writing). They practice authentic reading, listen to the teacher's explanation and speak about the content and they write certain tasks to consolidate what they have previously listened to, read and spoken. Additionally, students interpret and evaluate the information provided, study and learn facts, and develop a variety of receptive and productive procedures which prepare them for the variety of academic demands they will have to face with (Madrid, and García 2001).

\subsubsection{Benefit of Content based instruction}

The use of content-based instructional approaches in language learning has increased radically during the past two decades and its benefits have been recorded on numerous occasions via studies conducted on successful programs within a wide range of educational environments (Jiyoung 2005). According to Curtain and Pesola (1994) as cited in Silvia 2007 content-related instruction, the foreign language teacher uses concepts from the regular curriculum to enrich the program with academic content. The curriculum content is chosen to provide a vehicle for language learning, to reinforce the academic skills needed by the students, intended to foster the integration of language and content, viewing language as a medium for learning content and content as a source for learning and improving language.

Content based language teaching has two instructional types, content-Driven and Language-Driven Instructions(Met 1999). These two positions on a continuum and uses it to distinguish between content and language driven programs, models, and approaches. As stated in the continuum, content-driven instruction teaches content in the target language, considers content as its priority and language learning as its secondary objective, seeks to achieve content-based objectives, allows teachers to select language objectives, and evaluates learners based on content knowledge. Language-driven instruction, on the other hand, uses content to learn the target language, considers language learning its primary objective and content as matter to be acquired incidentally, seeks to achieve language based objectives, evaluates learners on language learned through content and does not hold learners accountable for content material knowledge.

Therefore, we can conclude that integration a continuum of content and language driven

\section{A. Content-Driven}

- Content is taught in L2.

- Content learning is priority.

- Language learning is secondary.

- Content objectives determined by course goals or curriculum.

- Teachers must select language objectives.

- Students evaluated on content mastery. 


\section{B. Language-Driven}

- $\quad$ Content is used to learn L2.

- Language learning is priority.

- Content learning is incidental.

- Language objectives determined by L2 course goals or curriculum.

- Students evaluated on content to be integrated.

- Students evaluated on language skills/proficiency

Furthermore, content-Based Instruction $(\mathrm{CBI})$, by providing both content and language, has been acknowledged as a key approach that can benefit English language learners and help them reach both their content and form goals. It uses to explore new ideas, knowledge, and language (Jiyoung 2005) and it can help learners develop their language skills for academic achievement as well as overall development of knowledge through meaningful content (Crandall, 1999). It fits in well with broader principles of language teaching and learning, and it can be applied in various situations. It removes the arbitrary distinction between language and content, offers optimal conditions for second language acquisition by exposing learners to meaningful, cognitively demanding language and also it provides pedagogical accommodation to learner proficiency levels and skills (Brinton, Snow and Wesche 1989).

Moreover, the concurrent teaching of content and language through CBI provides a meaningful context for language teaching and learning to occur and exposes students to a significant amount of comprehensible language while learning content. It encourages them to engage in real communicative interactions in the target language which has a crucial role in second/ foreign language (Byrnes, 2005; Gass \& Mackey, 2006; Wesche and Skehan, 2002). CBI is highly practical curricular methodology and it gives natural way of learning/ teaching of language skills in integrative manner (Brinton, Snow, and Wesche, 1989).

Generally, CBI is considered as the most important curriculum in language teaching approach as long as it is used in a suitable language teaching situation (Richards \& Rodgers, 2001). Teachers use interesting topics rather than grammar rules, vocabulary spheres, contextual situations as the frame work for instructions(Maria,2004). It has been implemented following different patterns and models of organization (Brinton, Snow and Wesche, 1989).In this connection ( Scarcella, R, and Oxford, R, 1992 and Davies,S. (2003) ) also believes that, there are at least three general models of content-based language instruction, such as themebased, adjunct-based, and sheltered-based.

\subsubsection{The Theme-based Model}

The theme-based model integrates the language skills into the study of a theme or modules and the language operates as the subject matter. The theme must be very interesting to students and must allow a wide variety of language skills to be practiced. CBI courses are completely language-driven, language-accountable, and taught by language teachers. This is the most common and useful CBI model at beginning and intermediate levels of language education (Dupuy, 2000; Weigle \& Jensen, 1997). Brinton, Snow, \& Wesche, 1989 cited in Ali Reza Abasi (2012) such a course can be demonstrate as follows:

"Week lesson plan theme-based language course might be organized around
numerous unrelated topics, such as heart disease, noise pollution, solar
energy and etc. For example, the topic might be initially presented as
a reading selection, the topic and vocabulary would then be recycled in
guided discussions, related audio- and/or videotaped materials would
provide the basis for listening activities, and, finally, a writing assignment
synthesizing the various source materials would round out the topic unit", p.
15)

The theme-based model lies closer to the language-driven position and the principal goal of this model is developing target language skills. It courses are taught not by a content teacher nor co-teachers, but a language teacher who has expertise in language education. Theme-based lessons emphasize themes taken usually from a diverse range of learner interests. The choice of a global theme allows instructors more freedom in introducing various content materials which in turn provides learners with more opportunities to engage in the matter being learned. Content is introduced in relation to each chosen theme and learners become involved in using a variety of language skills in relation to the content (Jiyoung, 2005).

Generally, theme-based models have been most successful in EFL contexts with learners with intermediate to advanced levels of proficiency. Theme-based instruction works effectively because the themes are chosen for their relevance, importance, and interest to the students. (Jiyoung, 2005). These can be used as an instrument for students' motivation (Crookes \& Schmidt, 1989).

\subsubsection{Adjunct Model}

This model is usually used by ESL teachers. Its main objective is to prepare students for "mainstream" classes. They emphasize the acquisition of specific target vocabulary and some necessary skills, so as to get a better understanding of the regular classes (Gabriela 2015). Students are concurrently enrolled in two linked courses: a 
content course and a language course. Teachers of these two courses work collaboratively to ensure that students acquire the content base and the language skills necessary for successful learning of the content. In other words, adjunct approaches are both language and content-driven and students are simultaneously accountable to language as well as content (Andrade and Makaafi, 2001). Therefore, adjunct models require a collaborative effort between one content teacher and one language teacher. The two teachers are responsible for coordinating lessons based on content material and language used within each task(Jiyoung,2005,p.149).

\subsubsection{Sheltered Model}

In the sheltered model, the subject matter is taught in simplified English tailored to students' English proficiency level (Olga and Anastasia 2006). The sheltered CBI courses are mostly content-driven and are taught by subject matter specialists totally in the target language. This model involves various content courses such as psychology, geography, or math, exclusively for second language learners in order to 'shelter' them from native-speaking students and create homogenous classes entirely made up of language learners. Normally, content specialists who teach such courses have either been trained in issues of language learning (Snow, 1997, 2005) or helped by language professionals in using linguistically sensitive instructional strategies in order to deliver the subject matter more accessible to students. Some of the pedagogical modifications used in sheltered courses, for example, include careful selection of texts in terms of their organization and clarity, gearing lectures more closely to the readings, making certain linguistic adjustments to accommodate students' still developing listening proficiency and placing greater emphasis on receptive skills and less on speaking and writing as the overall course requirements.

Sheltered language strategies allow students to develop knowledge of subject matter areas through their English language. Through these strategies, teachers ensure that lessons are comprehensible to learners of different English language proficiency levels and also provide English language development(Hernandez 2003). In this regard Getu (2015) confirms that The content instructor is responsible for content instruction and is aware of learner's language barriers. This kind of course aims to help student's master content knowledge while incidental language learning occurs.

An effective sheltered instruction technique is to portray from the learners' background knowledge in the area of study. While the teacher relating the subject matter to the students can involve not only asking questions regarding what they have learned in school about the content but also obtain what students know about the topic from their own life experiences and personal connections. The teacher may observe that students lack sufficient background knowledge or connections about the subject, then lesson planning needs to present basic foundations of the subject matter through the use of visuals, realia, guest speakers, field trips or related readings. During content instruction, complex concepts and information can be clarified through demonstrations and experimentation. In other words, lesson delivery should include simplification of explanations and vocabulary development by means of showing examples, demonstrating differences and similarities, and speaking with simpler syntax and added gestures (Hernandez, 2003). Students learning content via a new language may have also difficulties with cognitively demanding tasks or with discussions presented in context-reduced situations with few external supports for meaning. Students may want to participate and share their view, but they may have difficulty devising a response or include appropriate content vocabulary learned in class. So, it is important for the teacher to frequently check learners' comprehension by collecting and evaluating student work samples in the subject area.

Generally, the primary aim of this model is to help learner's master subject content. The sheltered model enables teachers to deliver more comprehensible subject content to foreign language learners (Getu, 2015) and also content lessons are of priority and language secondary. Learners in a sheltered subject matter course will therefore, need to concentrate on understanding the subject matter and be responsible for exams consisting of subject matter knowledge. Language, being a secondary objective, is dealt with within content lessons according to student needs (Jiyoung,2005).

\subsection{Task-Based Instruction}

\subsubsection{Definition of Task Based Instruction}

According to Nunan (1989) as cited in Aquilino 2004, task is a piece of classroom work which involves students in comprehending, manipulating, producing or interacting in the target language, while their attention is principally focused on meaning rather than form. Tasks are defined in terms of what the learners will do in class rather than in the world outside the classroom (David 1989).

In the early 1980s and much emphasis on learners' communicative abilities over the last two decades, the term task-based language teaching (TBLT) came into prevalent use in the field of foreign language acquisition in terms of developing process-oriented syllabi and designing communicative tasks to promote learners' actual language use. Tasks are defined as activities that can stand alone as fundamental units and that require comprehending, producing, manipulating, or interacting in authentic language while attention is principally paid to meaning rather than form (Nunan, 1989). Oxford, 2001 as cited in Olga and Anastasia (2012) expresses that: 
"In task-based instruction, basic pair work and group work are often used to increase student interaction and collaboration. More structured cooperative learning formats can also be used in task-based instruction. In taskbased instruction, students participate in communicative tasks in English. In other words it stresses doing tasks that require communicative language use.

Many language educators express that TBLT is compatible with three different things related to classes' room practice. It looks like a learner-centered educational philosophy (Ellis, 2003; Nunan, 2005; Richards \& Rodgers, 2001); it consists of particular components such as goal, procedure, specific outcome (Murphy, 2003; Nunan, 2004; Skehan, 1998); it advocates content-oriented meaningful activities rather than linguistic forms (Beglar and Hunt, 2002; Carless, 2002; Littlewood, 2004).

It is relevant to all levels of language proficiency, but the nature of the task varies from one level to the other. Tasks become increasingly complex at higher proficiency levels. For instance, beginners might be asked to introduce each other and share one item of information about each other. More advanced students might do more intricate and demanding tasks, such as taking a public opinion poll at school, the university, or a shopping mall (Oxford, 2001). She also describes the applicable model framework of task-based instruction in the classroom. By emphasizing the importance of pair and group work to increase student interaction and collaboration, she gives examples of the students' tasks such as working together to write and edit a class newspaper, develop a television commercial, enact scenes from a play, or take part in other joint tasks. She continues her standpoint by giving formative and structured cooperative learning formats which can also be used in task-based instruction (2001) .

In current situation the ubiquitous language practice exercises for groups or pairs of learners typically combine listening and speaking, reading and speaking, or reading, writing, and speaking. Such integrated classroom activities include, for example, listening to language tapes, playing games, or working on information gap and problem-solving exercises. These types of practice require learners to engage in interaction and integrated language usage because group- or pair-work can be carried out only if the participants share and discuss, or read and pool their information (Oxford,1990).

According to Richards 2006 there are at least two types of tasks in integrated skills teaching. These are pedagogical tasks and real world tasks. Two of them are briefly reviewed below.

\subsubsection{Pedagogical Tasks}

Pedagogical task is an activity which is carried out as the result of processing or understanding language (i.e. as a response). For example, drawing a map while listening to a tape, listening to an instruction and performing a command may be referred to as tasks. Tasks may or may not involve the production of language. A task usually requires the teacher to specify what will be regarded as successful completion of the task. The use of a variety of different kinds of tasks in language teaching is said to make language teaching more communicative. It provides a purpose for a classroom activity which goes beyond the practice of language for its own sake (Richards, et al. 1986 as cited in David 1989).

Pedagogical task is a work plan that requires learners to process language pragmatically in order to achieve an outcome that can be evaluated in terms of whether the correct content has been conveyed. It requires them to give primary attention to meaning and to make use of their own linguistic resources, although the design of the task may predispose them to choose particular forms. A task is intended to result in language use that allows a resemblance, direct or indirect, to the way language is used in the real world (Ellis 2003 as cited in Richards 2006)

According to Richard, (2006), pedagogical tasks are specially designed classroom activities that are intended to require the use of specific interactional strategies and may also require the use of specific types of language skills (grammar, vocabulary). A task in which two learners have to try to find the number of differences between two similar pictures is an example of a pedagogical task. The task itself is not something one would normally encounter in the real world. Breen (1987) also confirms that task is a range of work plans which have the overall purposes of facilitating language learning from the simple and brief exercise type, to more complex and lengthy activities such as group problem-solving or simulations and decision-making.

\subsubsection{Real-world Tasks}

Real-world tasks are tasks that reflect real-world uses of language and which might be considered a rehearsal for real-world tasks. A role play in which students' practice a job interview would be a task of this kind Richard (2006). Real-world tasks are tasks that are brought into a classroom after the learners' need had been analyzed in terms of target task(s) they want to perform outside a classroom This means the learners perform tasks (for example, reading technical manual, reporting an experiment) which are directly related to their need of tasks in the real world Long and Crookes, (1992) et. al as cited in Alemayehu (2008).

Generally, task-based teaching is probably the most widely adopted model of integrated language teaching today, and it is often considered to be the closest classroom situation of real-life interaction (Hinkel, 2006). Many Scholars such as (Oxford, 2001; McDonough \& Shaw, 2003) argue that language learning tasks need to be designed in an integrated manner. This is because more students are engaged in language tasks that integrate 
language skills, and they can learn(gain) better knowledge (Hulstijn \& Laufer, 2001). When the four primary skills of language: listening, reading, speaking and writing are interwoven during instruction, it helps us real-life language use and it also paves the way for most advantageous language learning to take place (Oxford, 2001).

\section{Techniques of Integrative Language Skills Teaching Approach}

The integrative language teaching approach is intended to provide an authentic language environment for the learners to develop listening, speaking, reading and writing skills in a meaningful context Oxford (2001).

The question that immediately comes to mind is how EFL instructors can integrate these strands to produce successful classes. In this regard, Oxford (2001) considers three key factors. First, the instructor's teaching style should address the learning styles of the learners as much as possible. Second, the learner should be motivated to learn the target language. Third, the setting should provide resources and values that strongly support the teaching of the language. If these strands are not woven together effectively, the EFL class is likely to become almost as boring as a teacher-centered class.

In other words, EFL teachers may use varies techniques to integrate language skills proceed the lesson effective ways. They should facilitate the situations in what way these skills are implemented in the actual classroom situation. In this sense, EFL instructor should learn more about the various ways to integrate language skills in the classroom, either by applying TBI or CBI separately or the combination of the two. As EFL professionals, we should think over our approach to the teaching of EFL in our environment and evaluate the extent to which the skills can be integrated. They should be to select appropriate instructional materials, audiovisual aids that promote the integration of four language learning skills. The teachers may begin his /her teaching with a single skill and then integrate the other language skills through proper activities (Oxford, 2001). Activities by its self-used by teachers in the integrated language teaching approach are real-life activities and situations and thus create an interactive learning environment. A teacher lets his students in communication situations that have to as real as possible so that students realize the importance of learning the foreign language Hungyo and Kijai, (2009) as cited in Elena and Lorena, (2011).

Besides, the English language learners must actively participate in the activities so that the learning process may go on. The environment conducive for learning will also be helpful to language in making language learning a success. In other words when the teacher uses different activities in integrative language skill teaching approach students can be successful in language learning. Creating an authentic learning environment through group work and communicative activities will prepare students for real-life situations, making connections between life and learning (Oxford, 2001).

Nunan (2001) explains that, the first step to integrate skills is to identify the contexts and situations in which learners will need to communicate. After the communicative events are identified in general terms, the next phase should work toward learners' functional goals along with the linguistic elements required to achieve them. According to Nunan(2001), in integrated instruction, language skills are taught and practiced depending on the students' learning objectives, rather than in the context of the four separate instructional areas. Mendelsohn (1998) also stresses the needs to develop students' overall strategic competence, assuming that the awareness of strategies and the effective use of them will lead to successful learning. Clearly, strategy use and instruction in the four language skills allow students to be aware of monitor and evaluate their learning process, reduce anxiety and improve both attitudes and motivation. Moreover, these four language skills include associated skills, such as knowledge of vocabulary, spelling, pronunciation, syntax, meaning, and usage. Thus, the skill strand of the tapestry can lead to effective EFL communication when all the skills are interwoven during instruction. If these language skills are effectively interwoven, EFL students are likely to become communicatively competent (Oxford,2001).

Generally, skills integration as an important vehicle for language learning. Therefore, teachers should encourage their students to make a regular effort to practice in skill integration classes as well as outside the classroom, and help them choose appropriate materials, to create awareness of learning strategies, use different exercises and activities and also it would facilitate interaction, task continuity, natural way of language use and task outcomes (Nunan 2005). If the learners involve, in the classroom performance they may become autonomous.

\section{Summary}

Integrated language skills teaching approach is a whole language approach. That is, if a lesson deals with reading skills, then, it will also deal with listening, speaking, and writing skills. It emphasizes on communication purpose in addition to academic success (Hungyo and Kijai 2009 as cited in Elena and Lorena 2011). The four English language skills can be taught integratively in the actual classroom situation via integrative approach. For example, by practicing conversational skills the learner can focus not only on speaking but also listening, in order to reply and ask appropriate follow-up questions. All language skills are considered and to be essential components to develop the communicative competence of students, the skills should be taught together via 
interactive language teaching approach. Thus, the approach advocates integration of all language skills in actual classroom situation (Crystal, 2003). In other words, integrated language skill teaching approach is the natural way of learning a language. In real life communication, language skills are rarely used in isolation; it is a rare situation where one of the four skills occurs alone. For example, to engage in a conversation, one needs to be able to speak and comprehend at the same time (Jing, 2006). Besides, integrative language teaching approach is consistent with the communicative language teaching approach as both emphasize meaningful and authentic language use and link oral and written language development (Chen S, 2007).According to Larsen-Freeman (2000), Savignon (1991) and Oxford, Lavine and Crookall (1989), the principles of communicative language teaching emphasize the importance of using a language to communicate in order to learn it. Similarly, the integrative approach focused on teaching language skills integratively in order to make students use the language skills meaningfully in real life situation. In the use of language skills one skill will reinforce another; we learn to speak, for example, in part by modeling what we hear and learn to write by examining what we can read (Brown, 2001). To achieve the benefits of integrated language teaching, language teachers should teach language skills by integrating the skills. Furthermore, various methods and techniques were developed.

\section{References}

Afnan,M.(2014), Kumaravadivelu's Framework as a Basis for Improving English Language Teaching in Saudi Arabia: Opportunities and Challenges: Vol. 7, No.4; Canadian Center of Science and Education.

Brown, H.D. (2001). Teaching by Principles: An Interactive Approach to Language. Pedagogy 2nd Ed., Newyork: Pearson Education.

Crystal, D. (2003). English as a global language. 2nd ed: Cambridge University Press.

Hinkel, E. (2001). Building awareness and practical skills for cross-cultural communication in ESL/EFL. In M. Celce-Murcia (Ed.), Teaching English as a second or foreign language (3rd ed., pp. 443-458). Boston: Heinle \& Heinle.

Olga, T and Anastasia, K(2012).Developing the communicative Competence of the university teaching staff: an integrative skill Approach.

Oxford, R. (2001). Integrated skills in the ESL/EFL classroom. ERIC digest ERIC Clearinghouse on Languages and Linguistics.

Jing, W. (2006). Integrating Skills for Teaching EFL -Activity Design for the Communicative Classroom, Sino-US English Teaching. V. 3, No.12 (Serial No.36).

Strang, R. (1972). Developing oral expression. In H. D. Funk, \& D. Triplett (Eds.), Language Arts in the Elementary School: Readings (pp. 287-293). Philadelphia: J. P. Lippincott Company. 